\title{
Para una lectura crítica de Hacia la crítica de la violencia de Walter Benjamin: Schmitt, Kafka, Agamben
}

\author{
Critique of Walter Benjamin's Critique of Violence: \\ Schmitt, Kafka, Agamben \\ EdUARdo MaUra Zorita * \\ Universidad Complutense de Madrid
}

RESUMEN. El propósito de este artículo es evaluar críticamente la lectura de Giorgio Agamben del ensayo sobre la violencia de Walter Benjamin, muy particularmente en sus relaciones con otras obras relevantes de Franz Kafka y Carl Schmitt. A partir del intento de Agamben de derivar la «nuda vida» y ciertas determinaciones de su homo sacer del texto de Benjamin, buscaré situar la crítica de la violencia en el lugar que le corresponde, así como repensar la propia obra de Agamben, tan valiosa en algunos puntos como discutible en otros.

Palabras clave: violencia, Benjamin, Agamben, escatología, excepción

\section{Ante la ley: las políticas de la violencia de Franz Kafka y Carl Schmitt}

Benjamin redactó Zur Kritik der Gewalt en diciembre de 1920 con vistas a su publicación en la revista Archiv für Sozialwissenschaft und Sozialpolitik, de gran difusión en la época y que contaba, entre otros, con colaboradores de la talla de Carl Schmitt. A primera vista, se trata de un texto singular en la producción benjaminiana. $\mathrm{Y}$ es que no es habitual que
AbSTRACT. The purpose of this article is to assess in a critical fashion the way Giorgio Agamben reads Walter Benjamin's essay on violence. I will particularly focus on the way Agamben relates this essay to other works by Carl Schmitt and Franz Kafka. Given his effort to steer Benjamin towards the concepts of «mere life» and certain qualities of the homo sacer, I will try to relocate Benjamin where his political essay belongs and, at the same time, re-read Agamben at his strongest points, but also at his weakest.

Key words: violence, Benjamin, Agamben, eschatology, exception.

Benjamin se aproxime a una materia tan importante para él como la ley, en todas sus dimensiones, sin recurrir de alguna manera a categorías estéticas o literarias (véanse, en este sentido, el Trauerspielbuch o los importantes ensayos sobre Las afinidades electivas de Goethe y Franz Kafka). Sin embargo, tanto en su configuración lingüística, amparada siempre en la escritura dialéctica como expresión bifronte (derecho natural / derecho positivo, primero, y violencia mítica / violencia pura, después) como en la exposición 
de sus motivos, la escritura de Benjamin se presenta en su máximo esplendor. La recepción del texto ha sido tan compleja como su trama: inicialmente ignorado por los editores en favor de piezas más rutilantes, no contó siquiera con la aprobación de Peter Szondi, el cual, al ser preguntado por la selección de textos que debía aparecer en la editorial Suhrkamp bajo el rótulo Schriften, lo descartó junto con el «Karl Kraus» en favor de otros como «Destino y carácter» ${ }^{1}$. Más adelante, sin embargo, la crítica de la violencia ha adquirido un rango elevado entre los estudiosos de Benjamin, muy particularmente en lo que atañe a la cuestión del origen mítico de la ley y sus vínculos con la literatura de Kafka.

En general, diversos textos de Benjamin han tratado de iluminar aspectos relacionados con la ley. Sin embargo, sólo la crítica de la violencia nos ofrece un tratamiento sistemático del tema. Benjamin, desde el comienzo, exige cautela, ya que el propio título impone una doble lectura. Gewalt, en alemán, significa tanto violencia, en sentido enfático, como poder, en el sentido de poder establecido. Así, el propósito del ensayo es doble: primero, establecer los fundamentos para una distinción entre violencia mítica y violencia divina. Segundo, elevar desde dicha dicotomía una crítica de largo alcance de las estructuras del poder establecido. El punto de partido de esta lectura de Zur Kritik der Gewalt (1921) es la idea de que Benjamin que aspira a una estrategia revolucionaria que el término mesiánico no agota en su totalidad $^{2}$. En la crítica de la violencia, las fuerzas revolucionarias miran hacia el Paraíso. El juicio divino les presta una inmediatez que Benjamin reclama y que remite al lenguaje adánico y la facultad de nombrar. A la afinidad, en definitiva, entre la palabra y la cosa. El Paraíso, lejos de ser una categoría mesiánica como tal es, en realidad, epítome de una metafísica de la presencia: la violencia divina comparece en las páginas finales de la crítica de la violencia como logos en acción, como justicia suprema, a saber, como justicia sumarísima, carente de juicio y más allá de la vista de los hombres. La violencia pura, por mor de lo vivo, se presenta como «insignia y sello»y no como acto de guerra santa. Como en las páginas finales de $\mathrm{El}$ proceso, para ella es como si la vergüenza fuera a sobrevivirnos.

La mención a Kafka no es en absoluto casual para nuestro propósito. En una importante carta a Benjamin del veinte de septiembre de 1934, en la que Scholem trata de aclarar diversos aspectos de la obra de Kafka basándose, precisamente, en las cargas histórico-naturales que los personajes de Kafka soportan, se puede leer: «¿Me preguntas qué entiendo por "la nada de la revelación"? Por ella entiendo un estado en el que la revelación aparenta no tener significado pero, aún, se afirma a sí misma, en el que tiene validez pero no significado [in dem sie gilt, aber nicht bedeutet]. Un estado en el que la riqueza de significado se ha perdido y lo que se encuentra en proceso de comparecer (pues la revelación es precisamente tal proceso) sin embargo no desaparece, pese a verse reducido a un punto cero de contenido, por así decirlo» ${ }^{3}$. Llama la atención, a este respecto, el parecido de familia entre ese estado de validez sin significado, que para Scholem culmina en su retracción a un punto cero de contenido, con la figura política del estado de excepción, tal y como Carl Schmitt la ha configurado y, a efectos de la crítica de la violencia, la parábola kafkiana «Ante la ley». Procediendo en orden inverso, podríamos hablar del relato de Kafka como síntoma de una afinidad electiva entre Kafka, Scholem y Benjamin por la que el judío secular Kafka (o Benjamin) asume la distinción paulina entre letra y espíritu, 
esto es, interioriza su exposición a una letra muerta que ha perdido valor espiritual y que, en sus cuerpos, aparece grabada violentamente en las letras de la circuncisión y no, por el contrario, en la escritura del corazón ${ }^{4}$. La opacidad de la ley se asemeja aquí a la figura del campesino de Kafka que, perplejo ante la apertura (de la puerta que conduce a la ley) se obsesiona con su guardián y permanece sentado junto a él hasta que, ciego y agotado, percibe un resplandor que surge del interior: «Pero entonces advierte en medio de la oscuridad un resplandor que, inextinguible, sale por la puerta de la Ley. Le queda poco tiempo de vida. Antes de su muerte se le acumulan en la cabeza todas las experiencias vividas aquel tiempo hasta concretarse en una pregunta que todavía no le había hecho al guardián. Le indica por señas que se acerque, pues ya no puede incorporar su rígido cuerpo [...] "Todos aspiran a entrar en la Ley", dice el hombre, "¿cómo es que en tantos años nadie más que yo ha solicitado entrar?". El guardián advierte que el hombre se aproxima ya a su fin y, para llegar aún a su desfalleciente oído, le ruge: "Nadie más podía conseguir aquí el permiso, pues esta entrada sólo estaba destinada a ti. Ahora me iré y la cerraré"» ${ }^{5}$. La incapacidad de decidir entre la potencia-de-sí y la potencia-de-no del campesino de Kafka ha podido ser interpretada como la imposibilidad crónica de discernir que inaugura el estado de excepción. La pregunta entonces, en lo que a Benjamin concierne literalmente, sería: ¿es asumible el presupuesto kantiano de la forma de la ley que, en su pretensión de universalidad, rige con total independencia de su contenido? ¿No es acaso esto lo que le ocurre al campesino de Kafka, que la ley no les exige nada? ¿Acaso significa algo para él? Si la ley, en su vínculo indisoluble con la violencia jurídica, como parece sugerir Benjamin, es también vigencia sin significado, entonces tiende a coincidir con la mera vida y es indiscernible de ella. La tesis octava «Sobre el concepto de historia», por la que había que hacer efectivo el estado de excepción (que ha sido siempre regla para los oprimidos), se puede leer ahora como pretensión de eliminar la relación entre vida y ley, resolviéndola mediante la transformación de la vida en ley. Esta interpretación, de cuño agambeniano, alcanza su máxima expresión en la siguiente fórmula: «A la impenetrabilidad de una escritura que, convertida en indescifrable, se presenta ahora como vida, corresponde la absoluta inteligibilidad de una vida enteramente resuelta en escritura» ${ }^{6}$. Esta relación es similar a la de escritura y vida en la correspondencia con Scholem (carta del 11 de agosto de 1934) y similar a la afirmación de Benjamin por la que la puerta de la justicia no es el derecho que se practica, sino el que se estudia (el que se lee, el que se descifra, como la escritura que, sin su cifra, coincide meramente con la vida). En Kafka, la ley, como la escritura, se confunde con la vida. A su vez, el nuevo abogado de Benjamin ${ }^{7}$ estudia un derecho impotente, un derecho que, carente ya de vínculos con la violencia y el poder, sólo puede parecerse, proféticamente, al derecho mesiánicamente cumplido. Pero este derecho impotente no es la justicia misma, sino la puerta que conduce a ella. $\mathrm{Y}$ en este ámbito nuevo, el derecho tiene un nuevo uso que nos es desconocido, bajo una justicia en la que el mundo aparece como un bien ya inapropiable por el estado o, incluso, indecidible jurídicamente. Un mundo diferente en el que el estudioso y el jugador marcan la pauta.

La impenetrabilidad, propia de la tarea del estudioso, y la incapacidad de discernir, propia del jugador intuitivo, son categorías que, a continuación, vincularemos con la teoría de la soberanía de Carl Schmitt. En su estudio La dictadura, 
Schmitt propone una distinción entre dictadura comisarial y dictadura soberana: la primera, de índole pasajera, se caracterizaría por la autonomía de la norma de su aplicación. La Constitución, bajo este modelo, se suspende por mor de su propia conservación. Por el contrario, la dictadura soberana plantea el problema de una Constitución saliente que ya no existe efectivamente que, al mismo tiempo, no puede someterse a una nueva, ya que ésta sólo existe en forma mínima como poder constituyente. Es, por tanto, un estado en el que la ley se aplica pero no tiene vigor formal. El lugar de la soberanía, según Schmitt, es aquél en el que la oposición entre la norma y su aplicación alcanza su máxima expresión: el estado de excepción. De aquí el origen de su influyente definición de soberanía en Teología política: «Es soberano quien decide sobre el estado de excepción» ${ }^{8}$. El soberano, de esta manera, traza los límites del derecho desde fuera: «La decisión no es aquí la expresión de la voluntad de un sujeto jerárquicamente superior a cualquier otro, sino que representa la inscripción, en el cuerpo del nomos, de la exterioridad que anima y da sentido a éste. El soberano no decide entre lo lícito y lo ilícito, sino sobre la implicación originaria de la vida en la esfera del derecho o, en las palabras mismas de Schmitt, sobre la "estructuración normal de las relaciones de vida" de que la ley tiene necesidad» ${ }^{9}$. El derecho tiene carácter normativo porque crea su propia referencia en la vida real: la normaliza. Hay una indistinción entre lo externo y lo interno, entre el ejemplo y la excepción, entre la vida y el derecho, entre la prioridad de la culpa y la norma - culpa que no se refiere a la trasgresión sino a la vigencia de la ley, de ahí que la ignorancia no exima de su cumplimiento o, incluso, que no haya culpa sin norma, como rezan dos dichos famosos. Esta indistinción es propia de la decisión sobe- rana sobre la excepción que es aquí entendida como forma originaria del derecho. «El orden jurídico, más que mediante la sanción del hecho transgresivo, se presenta a través de la repetición del mismo acto sin sanción alguna, es decir, como caso de excepción» ${ }^{10}$. Esta caracterización del soberano linda sustancialmente con la tesis octava de Benjamin en la que, como hemos visto, Benjamin reclama la necesidad, para luchar contra el fascismo, de producir el estado de excepción efectivo. Estoy de acuerdo con Agamben en que este paso no es sólo una radicalización de la tesis del Trauerspielbuch de la indecisión soberana. Simplemente, Benjamin toma conciencia de que la máquina schmittiana no puede funcionar si el estado de excepción efectivo (wirklichen Ausnahmezustand) se confundiera con la regla. Es cierto que el primado de la excepción, basado en ésta como una posibilidad de constitución de la esfera normal, está en Teología Política. Pero, ¿qué ocurre cuando excepción y regla se vuelven indecidibles? Este es el desafío que, según Agamben, Benjamin plantea a Schmitt. La decisión soberana, alcanzado el paso que Benjamin reclama, se fagocitaría a sí misma, puesto que ya no podría decidir sobre el estado de excepción sin decidir sobre sí misma. Aquí es donde, una vez determinadas las diferencias entre decisión soberana (en su desenmascaramiento por Benjamin como mantenimiento de la opresión) y violencia pura, hay que volver a precisar algunos elementos de la crítica de la violencia.

En una carta a Ernst Schoen, Benjamin define perfectamente lo que entiende por Reiheit (pureza), y que no será bajo ningún concepto algo sustancial: «La pureza de un ser no es nunca incondicionada ni absoluta, está siempre subordinada a una condición. Esta condición es diferente según el ser de cuya pureza se trate; 
pero no reside nunca en el ser mismo» ${ }^{11}$. Si aplicamos esta concepción a la violencia del ensayo de 1921, ésta no pertenece esencialmente a la acción violenta. Esto es, la diferencia entre la violencia pura y la violencia jurídica no reside en su propia condición de violenta, sino en algo que la determina desde fuera. En este caso, según afirma Benjamin, se trataría de su relación con el derecho y con la justicia. La violencia pura, en ese caso, no es medio para un fin, como lo era la violencia policial. Benjamin busca el quid de su crítica en la esfera de los medios, y no en la de los fines que estos persiguen. La violencia comparece como medio puro: un medio, que pese a ser considerado siempre como medio, permanece al margen de los fines. Lo que Benjamin busca es una violencia que no pudiera ser nunca medio justo o injusto de acuerdo con fines determinados. La pregunta es, ¿cómo se comporta un medio así? ¿Existe otra manera de vincular medios y fines? Igual que el lenguaje en el ensayo sobre el lenguaje de los hombres es sólo puro en tanto que comunicabilidad total y simple y esta lengua pura no es una lengua aparte, sino que reside en todas las lenguas existentes, la violencia pura sólo comparece en la reelaboración de la relación entre violencia y derecho. La violencia pura no se vincula ya con el derecho que establece o con el que mantiene, sino que deshace el vínculo: rompe la línea existente entre violencia y derecho. Es una violencia que, por tanto, no se ejecuta, sino que, simplemente, actúa.

\section{La lectura de la conspiración de Giorgio Agamben}

Así como hemos utilizado ya algunas herramientas exegéticas de Agamben para este ensayo de lectura de la violencia y la ley en Benjamin, creo que urge en este momento reconsiderar críticamente la lectura de Benjamin que Agamben reali- za en diversos pasajes de su Homo sacer. No solamente el estatus que Agamben ha alcanzado en el mundo académico lo aconseja, sino también el hecho de que su exégesis se ha convertido, en los últimos tiempos, en una suerte de cifra canónica de lectura.

En líneas generales, Agamben deriva su análisis de la sacralidad de la vida del concepto de mera vida que Benjamin alumbra en su crítica de la violencia. $\mathrm{Si}$ en el ensayo político de Benjamin la violencia jurídica está vinculada a la inculpación de la vida natural y la violencia pura o divina es sangrienta pero incruenta, precisamente a causa de lo vivo, en la obra de Agamben, «de la misma manera que la excepción soberana, la ley se aplica al caso excepcional desaplicándose, retirándose de él, así también el homo sacer pertenece al dios en la forma de la insacrificabilidad [...] La vida insacrificable y a la que, sin embargo, puede darse muerte, es la vida sagrada» ${ }^{12}$. Así, el desarrollo de la figura del homo sacer, inadvertidamente para Agamben, parece avanzar en dirección opuesta al ensayo de Benjamin. Sigrid Weigel ha apuntado algo similar cuando, de forma más restringida, recuerda que el propio Benjamin rechaza, tanto en la crítica como en los ensayos sobre Goethe, Franz Kafka y Karl Kraus, el uso de conceptos secularizados procedentes del orden de lo divino o, incluso, del texto bíblico, para luego ser transferidos directamente, sin ninguna mediación teórica, al contexto de la vida humana ${ }^{13}$. Además de esta apropiación indebida por parte de Agamben, nos concierne singularmente su lectura específica de la crítica de la violencia en la primera secuela de su Homo sacer, titulada Estado de excepción, en la que, partiendo de la dialéctica del carácter sagrado del hombre y el paradigma de la biopolítica, Agamben plantea la problemática del estado de excepción recompo- 
niendo las relaciones entre Schmitt y Benjamin en clave dialógica. El objetivo del ensayo de Benjamin, sostiene Agamben, es probar la realidad de una violencia fuera y más allá del derecho que, como tal, pudiera romper la dialéctica entre la violencia que funda derecho y la que lo conserva. Esta violencia, que se correspondería con la violencia pura o divina (o, en la esfera humana, revolucionaria) de Benjamin, se muestra incompatible con el derecho, que, obviamente, no puede tolerar tal cosa, a saber, una violencia fuera del derecho. Y no porque los fines de la violencia en su determinado sean incompatibles con el derecho, sino por el hecho de su existencia exterior al derecho (Benjamin, GS, p. 183). Garantizar a la violencia una realidad más allá del derecho implica la posibilidad de una violencia pura, cuyo carácter no será ya el de fundación o conservación, sino el de supresión del derecho. Así inauguraría el hombre una nueva época histórica. En otro lugar, Agamben sugiere que en el debate sobre el estado de excepción entre Benjamin y Schmitt, el primer paso ha de ser el análisis de la lectura de Schmitt de la crítica de la violencia. Partiendo de una aseveración de escasa entidad como los hábitos de lectura del propio Schmitt, Agamben arguye que es imposible que colaborador asiduo de la revista no reparase en el texto de Benjamin, siendo éste de tal naturaleza que el interés para él tuvo que ser enorme. De hecho, y aquí Agamben afina más en la argumentación casuística, Schmitt cita en sus escritos el número anterior y el posterior al que incluyó el texto de Benjamin.

La lectura de la conspiración que presta título a este apartado consistiría en leer la teoría de la soberanía de Schmitt como una respuesta a Zur Kritik der Gewalt, y no al revés, como la historia de la relación entre Schmitt y Benjamin ha sido tradicionalmente representada. $\mathrm{Si}$ bien no es mi intención en estas páginas negar la reciprocidad e íntima enemistad intelectuales entre ambos, tampoco me parece justo pretender perpetuar el modelo Horkheimer-Adorno, léase confrontación izquierda-derecha, de interpretación de la misma. Así, se puede considerar que la célebre carta de Benjamin a Schmitt que acompaña al ejemplar de Ursprung des deutschen Trauerspiels, que aquél le envió con motivo de su publicación en la editorial Rohwolt de Berlín en 1928, es un documento de primera magnitud, pero no lo es menos la cita de Teología política en el propio libro sobre el barroco y, por encima de todo, el recurso a la teoría de la soberanía de Schmitt como su cifra de lectura. La carta, desterrada inicialmente de la correspondencia de Benjamin, rezaba:

Reconocerá usted cuánta influencia ejerce su escrito Teología política tanto metódica como objetivamente sobre mi libro; pero lo que no puede usted saber es que su libro $L a$ dictadura y otros me han conmovido profundamente, hasta el punto de que mis intuiciones en estética y sus ideas sobre filosofía política coinciden ${ }^{14}$.

Y no es menos llamativa la secuencia que el Jacob Taubes ha descrito en su pequeño exergo «La historia Jacob Taubes-Carl Schmitt». Allí se menciona una conversación con Adorno, a propósito de la exclusión de esta carta, que, siempre según Taubes, se desarrolló así: "“Han salido ya dos volúmenes de cartas de Benjamin, ¿cómo es que esta carta no se ha impreso en ellos?". La respuesta — de Adorno - fue: "No existe tal carta". Y yo dije: "Teddy, yo conozco la letra, conozco la máquina con la que escribía Benjamin. No me cuente cuentos. Aquí la tengo". "Imposible". Típica respuesta alemana. Así que saqué copia y se la mandé. Y además había allí un archivero, el señor Tiedemann. Recibo llamada telefónica de Teddy: "Sí que hay esa carta, pero 
se había traspapelado"» ${ }^{15}$. El testimonio es suficientemente explícito.

Finalmente, se podría concluir que Schmitt fuera un aguzado lector de Benjamin no modifica, al menos sustancialmente, el hecho de que Benjamin adoptara algunos de sus conceptos como herramientas cognitivas, al igual que la teoría de la confrontación Schmitt-Escuela de Frankfurt no alcanza a explicar la fascinación de buena parte de sus miembros o seguidores con la figura de Schmitt. Es por tanto necesario separar lo propio de lo ajeno sin cercenar la palabra objetivamente ambigua. Esto es, resistirse a que la utilización de textos de Schmitt en el Trauerspielbuch de Benjamin determine la balanza de la relación Benjamin-Schmitt hacia la admiración de Benjamin por Schmitt, tanto como a leer a Schmitt como si la crítica de la violencia fuera referente casi único de Teología política, libro, por cierto, escrito un año después.

La estrategia de lectura de Agamben consiste, en este sentido, en la inversión de la relación a través del análisis del texto de Benjamin como piedra de toque. En cuanto al texto de Schmitt, es cierto que Benjamin no utiliza el término estado de excepción, sino otro (Ernstfall), que en Schmitt sirve como sinónimo de estado de excepción (Ausnahmezustand) en Teología Política. Asimismo, Agamben señala con razón que Benjamin utiliza el término decisión (Entscheidung) en un momento importante: «El derecho reconoce la decisión local y temporalmente determinada como categoría metafísica» ${ }^{16}$. Agamben trata de utilizar estas coincidencias como elementos que tejerían por sí mismos una trama entre Benjamin y Schmitt, lo cual es harto complicado si nos ceñimos a un texto de Benjamin particularmente singular. No creo que se pueda basar un vínculo tal en una disquisición sobre el vocabulario de ambos puesto que Benjamin, aunque más Benjamin que nunca, está sin embargo aquí fuera de quicio. El argumento de fondo, más allá de la escritura circunstancial, es que Schmitt, según Agamben, trataría de devolver la violencia pura y anómica a un contexto jurídico. Esto es, la estrategia inversa a la de Benjamin: «El estado de excepción es el espacio en que trata de aprehender la idea benjaminiana de una violencia pura y de inscribir la anomia en el cuerpo mismo del nomos. No puede haber, según Schmitt, una violencia pura, es decir absolutamente fuera del derecho, porque, en el estado de excepción, está incluida en el derecho a través de su propia exclusión»» ${ }^{17}$. Aquí es donde Agamben saca las garras de la interpretación: aparentemente, en Teología política Schmitt abandona lo que en La dictadura era la dicotomía básica: poder constituyente y poder constituido, sustituyéndola por el concepto de decisión. Agamben lee esto es términos de contraataque. La dicotomía violencia-que-funda-derecho / violencia-que-conserva-derecho sería el equivalente teórico benjaminiano a la dicotomía poder constituyente / poder constituido. Y más allá: Schmitt reelaboraría su propia teoría para desarrollar una teoría de la soberanía que neutralizara la figura benjaminiana de la violencia pura, configurando a su vez la idea de una violencia soberana, que, como la violencia pura de Benjamin, fuera un poder que no crea ni conserva derecho, sino que lo suspende allí donde, en el ensayo de Benjamin, la violencia pura lo suprimía. La soberanía pasa a ser el lugar de la decisión última, en contra de la tesis de Benjamin de la indecibilidad de todos los problemas jurídicos. Sólo así Schmitt asegura la relación en un contexto jurídico determinado entre anomia y derecho. La violencia pura, para Benjamin, no se decide. No está sujeta a una decisión. Igualmente, Schmitt aprecia el problema de la indecibilidad y, ante la dificultad de determinar los casos extre- 
mos de decisión, enfatiza la pertinencia de la decisión soberana.

Agamben pretende, desde este punto de vista, reelaborar todo el debate entre Schmitt y Benjamin, incluyendo el problema del soberano en el libro sobre el Trauerspiel alemán. Pero Benjamin, en perfecta consonancia con lo anterior, modifica, incluso aquí, donde aparentemente la deuda es mayor, la propia teoría de Schmitt. Lo hace para reintroducir la exclusión necesaria del orden jurídico contra la inclusión schmittiana. Cuando Benjamin cita a Schmitt en el Trauerspiel ya desecha la posibilidad de esta inclusión: «Es el soberano quien representa a la historia, sosteniendo en la mano el acontecer histórico como un cetro [...] Esta doctrina extrema del poder del príncipe fue en sus orígenes - pese al agrupamiento en torno a ella de los partidos contrarreformistas - más ingeniosa y más profunda que su versión moderna. Si el concepto moderno de soberanía acaba por otorgar sin reservas al príncipe un supremo poder ejecutivo, el barroco se desarrolla por su parte a partir de una discusión sobre el estado de excepción, y considera que la función más importante del príncipe consiste en evitarlo. Quien manda está destinado de antemano a detentar dictatorialmente el poder durante el estado de excepción, cuando la guerra, la rebelión $\mathrm{u}$ otras catástrofes así lo provoquen» ${ }^{18}$. Agamben lee excluir donde Benjamin, en mi opinión, quiere decir evitar, dando pie, sensus literalis, a toda esta polémica.

La idea de la dictadura tiránica en el Barroco, sintéticamente, no sería otra que la de una utopía en la que el acontecer histórico es finalmente dominado por las leyes naturales. Esta idea es desbrozada por Benjamin mediante la teoría de la indecisión soberana que ocupa las páginas siguientes. Allí plantea la imposibilidad del soberano barroco de decidir: lo que Benjamin hace es escindir el poder sobe- rano de su realización. Para el tirano del barroco, la decisión se vuelve casi imposible, lo cual se percibe en «ese complemento de la tiranía sanguinaria que es la indecisión» ${ }^{19}$. Citaré ahora otro pasaje relevante de Benjamin: «En el modo de pensar teológico-jurídico tan característico del siglo se expresa la exaltación de la trascendencia que subyace a los acentos provocativos que el Barroco pone siempre en el más acá. Pues a éste la idea de catástrofe se le antoja cabalmente antitética del ideal histórico de la restauración. Y sobre esta antítesis se acuña la teoría del estado de excepción [...] El hombre religioso del Barroco tiene tanto apego al mundo dado que se siente arrastrado con él hacia una catarata. No hay una escatología barroca; y justamente por ello sí hay un mecanismo que reúne y exalta todo lo nacido sobre la tierra antes de que se entregue a su final. El más allá es vaciado de todo aquello en que se mueve hasta el más leve hálito del mundo, y el Barroco le arrebata una profusión de cosas, normalmente sustraídas a cualquier figuración, que ahora en su apogeo saca a la luz con una figura drástica, a fin de despejar un último cielo y, en cuanto vacío, ponerlo en condiciones de aniquilar algún día en sí a la tierra con catastrófica violencia» ${ }^{20}$. Pues bien, Agamben lee aquí un desplazamiento del paradigma del milagro como estado de excepción al paradigma de la catástrofe y acusa a los editores de las Gesammelte Schriften de no haber percibido las implicaciones de este desplazamiento. Si bien, de nuevo, Agamben incurre en la secularización del milagro en catástrofe, es todavía más peculiar el argumento filológico: «Donde el texto benjaminiano rezaba: Es gibt eine barocke Eschatologie, "hay una escatología barroca", los editores, con singular menosprecio de cualquier cautela filológica, han corregido, Es gibt keine... "no hay una escatología barroca" ${ }^{21}$. Por mi 
parte, creo que los editores de Benjamin tienen razón: no hay una escatología barroca. De ahí la necesidad artificial, si se quiere, de un mecanismo de reunión de todas las criaturas antes de su final. Pero su final es la tesis octava, intuyo, no la acción directa divina-no-mediada. Que el Barroco no posee una escatología, además, Benjamin lo propone en otros lugares: "Mientras que tanto el misterio cristiano como la crónica cristiana presentan la totalidad del curso de la historia, la historia universal, como historia de la salvación, por su parte la acción principal y de Estado tiene que ver con una mera parte de lo que es pragmático acontecer» ${ }^{22}$. Más adelante, leemos: «La constitución del lenguaje formal del Trauerspiel puede entenderse como el desarrollo de las necesidades contemplativas inherentes a la situación teológica de la época. Y una de ellas, tal como comporta la desaparición de toda escatología, es el intento de encontrar consuelo a la plena renuncia a un estado de gracia en la consumada regresión al estado creatural [...] Mientras que la Edad Media exhibe la precariedad de la historia universal y la caducidad de la criatura como etapas en el camino de salvación, el Trauerspiel alemán se sume por entero en el desconsuelo de la condición terrena. Si reconoce una redención, ésta se encuentra más en lo profundo de dicha fatalidad que en la idea de consumación de un plan divino de la salvación» ${ }^{23}$.

La dialéctica de la escatología barroca existe realmente en el texto de Benjamin en forma de eschaton, de final del tiempo, pero las nociones que gravitan alrededor de ambas citas, unidas a la teoría de la soberanía, no permiten afirmar la existencia palmaria de una escatología barroca cuya inmanencia tomaría la forma de una cáscara vacía. Aquí, el carácter creatural de la naturaleza de la soberanía se vuelve contra Agamben: «Casi po- dría llevar como divisa cierto pasaje de Gracián que ilustra cuán escrupulosamente en los Trauerspiele ha de ajustarse el papel del príncipe al estereotipo y el extremo: "No hay medianía en los reyes. Son conocidos, o por muy buenos, o por muy malos" [...] El tirano y el mártir son en el Barroco las cabezas de Jano del coronado, las plasmaciones necesariamente extremas de la misma esencia principesca [...] La teoría de la soberanía, para la que el caso excepcional, con su despliegue de instancias dictatoriales, resulta ejemplar, obliga a complementar virtualmente la imagen del soberano en el sentido concreto del tirano, incluso en aquel caso que no lo exige la situación; exactamente del mismo modo en que a la aparición en escena del gobernante sólo excepcionalmente le faltarán el ornato completo, la corona y el cetro» ${ }^{24}$. Cuando Agamben busca en este soberano benjaminiano una tierra de nadie catastrófico-jurídica, olvida que la incapacidad de decidir del soberano es tal en cuanto habitante del reino de las criaturas, en su sometimiento a las leyes naturales, y no en su función política. No se justifica, ni filológica ni filosóficamente, la maniobra biopolítica de arrancar al soberano del Trauerspiel de su escenario para situarlo en la el Despacho Oval como, intuyo, Agamben aspira a hacer con su «olvido» de la dialéctica entre la función política del soberano y su realización como criatura. Para Benjamin la vida nuda, si como tal queremos considerarla, siempre queda fuera de la ley. $\mathrm{Su}$ exclusión no deja lugar a dudas.

Es cierto, por lo tanto, que Benjamin y Schmitt escriben en la misma constelación, como es igualmente plausible la influencia sobre éste de la definición del soberano como aquél que decide sobre el estado de excepción. Pero lo que no es admisible es que Benjamin y Schmitt mantengan una suerte de correspondencia secreta. El soberano se convierte en el 
ensayo de Benjamin en el lugar donde se aprecia más claramente la fractura del poder. Por eso se puede afirmar, sin comprometer a Benjamin con el paradigma biopolítico, que «el paradigma del estado de excepción ya no es, como en la Teología Política, el milagro, sino la catástrofe» ${ }^{25}$. Pero no se sostiene, al menos en esta formulación, que las motivaciones religiosas y la violencia mítica se hayan secularizado durante ese proceso. Agamben necesita de una escatología barroca para configurar textualmente el estado de excepción en el barroco en forma de catástrofe, y esto sólo puede ser porque necesita mantener la simetría Benja-
min-Schmitt. Esta idea se aleja del Benjamin de la crítica de la violencia tanto como el campo de fuerzas que constituye la secularización de los conceptos políticos de Schmitt, a saber, la correspondencia entre las categorías Rey y Dios. En Benjamin, y es aquí precisamente donde se impone el ensayo político sobre cualquier otro, incluso el Trauerspielbuch, el soberano es una criatura más. La lectura de la conspiración de Agamben se pierde, paradójicamente en una recta paralela que escamotea los antagonismos por conocer en la dialéctica Benjamin-Schmitt, en su contradicción objetiva, en definitiva, en su núcleo de verdad.

\section{NOTAS}

\footnotetext{
* Eduardo Maura es licenciado en Filosofía y Sociología por la Universidad de Deusto y escribe actualmente su tesis doctoral, centrada en las implicaciones filosóficas y potencial cognitivo de la filosofía de la historia de Walter Benjamin. Ha publicado artículos y reseñas sobre estas cuestiones en revistas como La Torre del Virrey (Valencia) o Logos (Madrid). Dirección postal: Facultad de Filosofía, Departamento Filosofía IV (ed. A). Ciudad Universitaria, 28040, Madrid. Correo electrónico: emauraz81@hotmail.com.

1 Szondi, P., Briefe, Frankfurt/M, Suhrkamp, 1993, p. 25.

2 Benjamin, W., «Zur Kritik der Gewalt», en Gesammelte Schriften, II/1, Frankfurt/M, Suhrkamp, 1972-1989, pp. 179-203. En adelante, GS remite siempre a Gesammelte Schriften. Salvo mención expresa las citas pertenecen a la edición española de Jorge $\mathrm{Na}$ varro Pérez, «Hacia la crítica de la violencia», en Obras, II/1, Madrid, Abada, 2007, pp. 183-206.

3 Benjamin, W., Gesammelte Briefe, II. Frankfurt/M, Suhrkamp, 2000, pp. 756-764 (la cita procede de la edición española, Benjamin, W. / Scholem, G., Correspondencia, 1933-1940, Madrid, Taurus, pp. 159160).

${ }^{4}$ Cfr. Santner, Eric L., On creaturely life. Benjamin, Rilke, Sebald. Chicago, University of Chicago Press, 2006, pp. 39-40.

5 Kafka, F., Obras completas, III. Narraciones y otros escritos, Barcelona, Galaxia Gutenberg, 2003, p. 193.

6 Agamben, G., Homo sacer. El poder soberano y la nuda vida. Valencia, Pre-textos, 2006, p. 75.

7 Cfr. Benjamin, W., «Franz Kafka», en Gesammelte Schriften, II/2. Frankfurt/M, Suhrkamp,

1972-1989, pp. 409-438. (traducción de R. Blatt, Para una crítica de la violencia y otros ensayos. Iluminaciones IV, Madrid, Taurus, 1999, p. 155). Otros textos relevantes de Benjamin sobre Kafka son «Franz Kafka: Beim Bau der Chinesischen Mauer», en GS, II/2, pp. 676-683 y la reseña «Max Brod. Franz Kafka», en GS, III, pp. 526-529.

8 Schmitt, C., «Teología política», en Carl Schmitt, teólogo de la política. Madrid: FCE, 2001, p. 24.

9 Agamben, G., op. cit., p. 41.

10 Agamben, G., ibid.

11 Benjamin, W., Briefe, op. cit., p. 205.

12 Agamben, G., op. cit., pp. 107-108.

13 Cfr. Weigel, «The Critique of Violence. Or, The Challenge to Political Theology of Just Wars and Terrorism with a Religious Face», en Telos, 135. Germany After the Totalitarianism (vol. 1). Summer 2006, pp. 61-76.

14 Citado en Taubes, J., La teología política de Pablo. Madrid, Trotta, 2007, p. 114.

15 Taubes, J., ibid.

16 Benjamin, W., GS, II/1, p. 189.

17 Agamben, G., Homo sacer, II/1. Estado de excepción. Valencia, Pre-textos, 2003, p. 82.

18 Benjamin, W., Obras, I/1, Madrid, Abada, 2005, p. 268.

19 Benjamin, W., op. cit., p. 275.

20 Benjamin, W., op. cit., p. 269.

21 Agamben, G., Excepción, op. cit., pp. 84-85.

22 Benjamin, W., op. cit., p. 283.

23 Benjamin, W., op. cit., p. 285.

24 Benjamin, W., op. cit., p. 273.

25 Agamben, G., Excepción, op. cit., p. 84.
} 